Article

\title{
Thermal Degradation Characteristic and Flame Retardancy of Polylactide-Based Nanobiocomposites
}

\author{
Kuruma Malkappa ${ }^{1}$, Jayita Bandyopadhyay ${ }^{1}$ and Suprakas Sinha Ray ${ }^{1,2, *(1)}$ \\ 1 DST-CSIR National Centre for Nanostructured Materials, Council for Scientific and Industrial Research, \\ Pretoria 0001, South Africa; MKuruka@csir.co.za (K.M.); jbandyopadhyay@csir.co.za (J.B.) \\ 2 Department of Applied Chemistry, University of Johannesburg, \\ Doornfontein 2028, Johannesburg, South Africa \\ * Correspondence: rsuprakas@csir.co.za; Tel.: +27-12-841-2388
}

Received: 20 September 2018; Accepted: 10 October 2018; Published: 16 October 2018

\begin{abstract}
Polylactide (PLA) is one of the most widely used organic bio-degradable polymers. However, it has poor flame retardancy characteristics. To address this disadvantage, we performed melt-blending of PLA with intumescent flame retardants (IFRs; melamine phosphate and pentaerythritol) in the presence of organically modified montmorillonite (OMMT), which resulted in nanobiocomposites with excellent intumescent char formation and improved flame retardant characteristics. Triphenyl benzyl phosphonium (OMMT-1)- and tributyl hexadecyl phosphonium (OMMT-2)-modified MMTs were used in this study. Thermogravimetric analysis in combination with Fourier transform infrared spectroscopy showed that these nanocomposites release a smaller amount of toxic gases during thermal degradation than unmodified PLA. Melt-rheological behaviors supported the conclusions drawn from the cone calorimeter data and char structure of the various nanobiocomposites. Moreover, the characteristic of the surfactant used for the modification of MMT played a crucial role in controlling the fire properties of the composites. For example, the nanocomposite containing $5 \mathrm{wt} . \%$ OMMT- 1 showed significantly improved fire properties with a $47 \%$ and $68 \%$ decrease in peak heat and total heat release rates, respectively, as compared with those of unmodified PLA. In summary, melt-blending of PLA, IFR, and OMMT has potential in the development of high-performance PLA-based sustainable materials.
\end{abstract}

Keywords: polylactide nanocomposites; intumescent flame retardancy; synergistic effect

\section{Introduction}

Polylactide (PLA) is one of the most promising sustainable polymers, owing to its excellent physical properties and mechanical capabilities, low cost, large production volume, and its transparency [1,2]. Because of these characteristics, PLA can be used in numerous applications, including paper coatings, fibers, films, foams, molded parts, and packaging [3-5]. However, some inherent properties of PLA, such as its low thermal stability and high flammability, limit its expansion into diverse applications, such as flexible electronics, constructions, and engineered plastic materials. Efforts have been made to improve the flammability characteristic of PLA by the introduction of Pand N-containing flame retardant components; nanomaterials such as montmorillonite (MMT) [6,7], graphene oxide (GO) [8], zinc oxide ( $\mathrm{ZnO})$ [9], molybdenum sulphide $\left(\mathrm{MoS}_{2}\right)$ nanosheets [10], and layered double hydroxide (LDH) [11]; and various synergistic combinations [12-14].

MMT is a type of multilayer aluminosilicate smectite clay with inorganic nano-sized particulates and widely used as a flame retardant (FR) for polymer nanocomposites because of its low cost, abundance, and excellent FR performance $[15,16]$. The MMT mainly inhibits the release of toxicants, heat, and smoke from the polymer composites during combustion [6]. However, compared with those 
of pristine MMTs, OMMTs show greatly improved FR properties. Pristine MMTs often exist in polymer matrices at the micro scale because they are hydrophilic in nature and do not have thermodynamically favorable interactions with the hydrophobic polymer matrices. Hence, the silicate platelets easily agglomerate or separate in the polymer matrix and it is difficult to achieve the required properties of the polymer nanocomposites (PNCs). To render MMTs compatible with hydrophobic polymer matrices, one must convert the normally hydrophilic surface to a hydrophobic one (commonly known as OMMTs), making the intercalation of polymer chains possible. Generally, this can be done by ion-exchange reactions with cationic surfactants, which lower the surface energy of two-dimensional silicate layers and improve the wetting characteristic of the polymer matrix, and result in a high silicate interlayer spacing. Some OMMTs are effective when added to various polymers, and significantly enhance the FR properties of the PNCs [17]. To pass a fire test, a polymer combined with OMMT must also be combined with other types of FRs because MMT alone cannot improve the fire properties of PNCs necessary for specific applications.

Melamine phosphate (MP), derived from the reaction between melamine (MEL) and phosphoric acid, is typically used as an intumescent FR (IFR), alone or combined with pentaerythritol (PER) in many applications, such as FR coatings and plastics. The typical IFR system comprises three types of components: an acid source, a char forming agent, and a blowing agent [18]. MP provides two of these three components, an acid and gas source, and MP can be an excellent FR for carbon sources containing polymers [19]. Casetta et al. [20] studied the efficiency of IFR formulations with PLA, which contained ammonium polyphosphate (APP), PER, lignin, and starch. The results showed that the FR activity of the PLA composites was greatly improved with a high loading of $40 \mathrm{wt} . \%$. Using a combination of microencapsulated ammonium polyphosphate (m-APP) and lignin as the IFR, a PLA/IFR composite was prepared, and it displayed excellent FR activity with a high loading of $23 \mathrm{wt} . \%$ [21]. Similarly, another FR system, using a PLA matrix consisting of polyhedral oligomeric silsesquioxane/m-APP and MMT / APP was studied [12,22]. The IFR contained a mixture of MP and PER used for polyolefins (such as polypropylene, PP), and the obtained composite exhibited excellent FR activity. It was also reported that the PP/MP composite system containing PER or its derivative compounds (DPER and TPER) displayed efficient FR activity through the formation of highly compact intumescent char, resulting in lower smoke and heat release rates, a high LOI value, and a UL-94 rating, compared with those of the PP composite containing MP alone [23]. There are various factors that influence the char formation mechanism during combustion, such as composition and ratios of IFR, their decomposition behavior, and the characteristics of the polymer resins [24]. The advantage of these IFR compositions is that the presence of PER inhibits the melamine sublimation and accelerates FR activity in the condensed phase with improved char residue and strength. However, to the best of our knowledge, there is no report on a PLA/IFR/clay composite system.

In this study, we used MP/PER as an IFR to inhibit melamine sublimation. We prepared PLA/IFR/ OMMT nanocomposites using two different types of OMMTs and different weight-percentage loadings. The resulting nanocomposite FR activity, toxic gas evolution, and thermal stability were characterized using thermogravimetric analyzer (TGA), cone calorimetry, and TGA hyphenated with Fourier transform infrared spectroscopy (TG-FTIR). We also studied the char morphologies of the char residues after cone calorimetry tests, and their FR behavior is thoroughly discussed.

\section{Materials and Methods}

\subsection{Materials}

PLA resin (7032D) with a specific gravity of 1.24 and an MFI (melt-flow index) of $13.81 \mathrm{~g} / 10 \mathrm{~min}$ $\left(190{ }^{\circ} \mathrm{C}\right.$, load $\left.=2.16 \mathrm{~kg}\right)$ was obtained from Nature Works LLC (Minnetonka, MN, USA). The pristine sodium montmorillonite (MMT) used in this study is Cloisite ${ }^{\circledR N a}$, purchased from Southern Clay Products (Gonzales, TX, USA). According to the supplier the cation exchange capacity (CEC) value of MMT is $92.6 \mathrm{meq} / 100 \mathrm{~g}$ of clay. Other chemicals, such melamine, phosphoric acid, triphenyl 
benzyl phosphonium chloride, tributyl hexadecyl phosphonium bromide, hydrochloric acid, silver nitrate, and pentaerytritol (PER) (Figure 1A, molecular structure) were purchased from Sigma Aldrich (Johannesburg, South Africa) and were used without further purification.

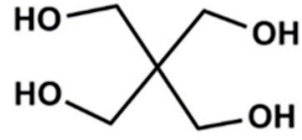

(A)

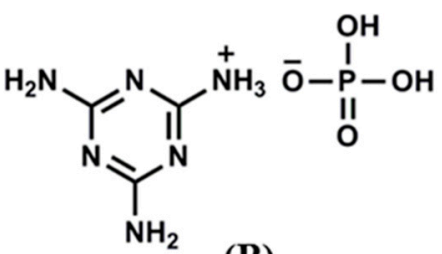

(B)

Figure 1. Molecular structure of (A) pentaerytritol and (B) melamine phosphate.

\subsection{Synthesis of Melamine Phosphate}

Melamine phosphate was synthesized based on a method reported in literature [25]. First, $15 \mathrm{~g}$ of melamine was dissolved in $200 \mathrm{~mL}$ of water and stirred for $1 \mathrm{~h}$ at $95{ }^{\circ} \mathrm{C}$. Phosphoric acid $(85 \mathrm{wt} . \%$, $4 \mathrm{~g}$ ) was dissolved in water separately, then this solution was slowly added to the reaction mixture, left for $3 \mathrm{~h}$ with continuous stirring, and allowed to cool and crystalize. Next, we separated melamine phosphate (MP) (Figure 1B, molecular structure) crystals by filtration and kept them in an oven at $100{ }^{\circ} \mathrm{C}$ for complete drying.

\subsection{Surface Modification of MMT}

The MMT was organically modified using two different types of phosphonium derivatives, following previously reported methods [26-28]. Briefly, the procedure is as follows: the MMT (5 g) was dispersed in water and stirred at $90{ }^{\circ} \mathrm{C}$ for $12 \mathrm{~h}$ to improve the silicate layer dispersion. Next, the required quantity $(6 \mathrm{mmol})$ of triphenyl benzyl phosphonium chloride surfactant was dissolved in water separately and then slowly added to the MMT mixture, followed by continuous stirring for $24 \mathrm{~h}$ to achieve complete intercalation of triphenyl benzyl phosphonium cations into the clay galleries. Then, the mixture was washed with water and ethanol until the chorine anions were absent in the filtrate in a chorine test with $\mathrm{AgNO}_{3}$ solution, and the resultant triphenyl benzyl phosphonium modified MMT was kept in oven at $100{ }^{\circ} \mathrm{C}$ for complete drying to prepare the nanocomposites. This triphenyl benzyl phosphonium modified MMT was designated as OMMT-1. To remove bromine from tributyl hexadecyl phosphonium bromide, after completely dissolving in water, we added $\mathrm{HCl}$ and stirred for $1 \mathrm{~h}$ to complete the exchange of bromine ions with chlorine ions, because of the low ion exchange capacity of bromine compared with that of chlorine, as shown in Scheme 1. Then, the above procedure was followed to prepare tributyl hexadecyl phosphonium-modified MMT and the modified MMT was designated as OMMT-2.

\subsection{Nanocomposite Processing}

A co-rotating twin-screw extruder with L/D of 40 (Process 11, Thermo Scientific, Waltham, MA., USA) was used for nanocomposite processing. A screw speed of $200 \mathrm{rpm}$ was used and the temperature profile for extruder was $160,170,190,190,190$, and $170{ }^{\circ} \mathrm{C}$, and that for the die was $190^{\circ} \mathrm{C}$. To avoid thermal degradation of the PLA matrix, there was a constant flow nitrogen gas in extruder. The extruded samples were collected via a water bath, pelletized, and then dried at $100{ }^{\circ} \mathrm{C}$ for overnight in a fan oven. Table 1 summarizes the composition and abbreviation of various samples used in this study. Finally, dried nanocomposite pellets were compression molded at $190{ }^{\circ} \mathrm{C}$ to prepare samples for various characterizations. 


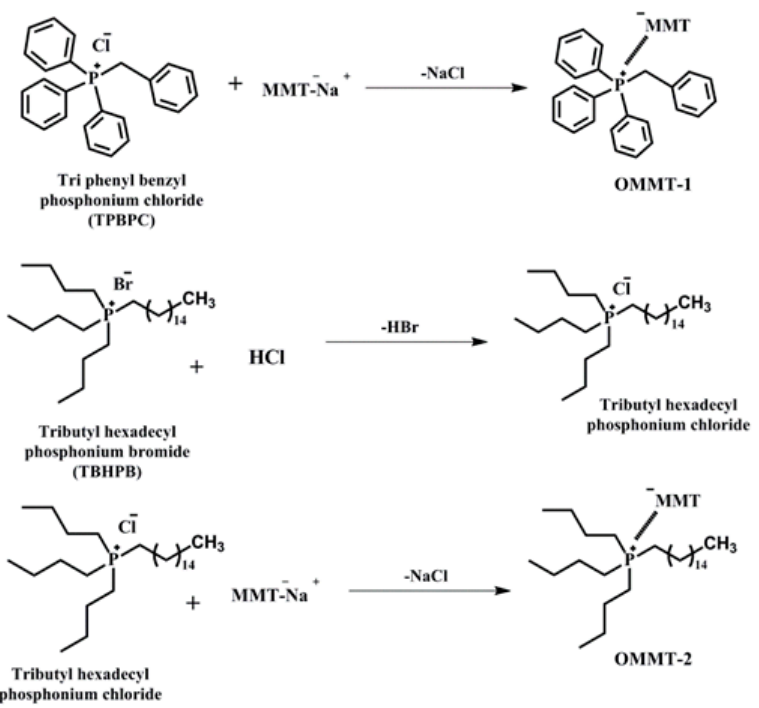

Scheme 1. Molecular structure of triphenyl benzyl phosphonium chloride and tributyl hexadecyl phosphonium bromide surfactants and the preparation of organically-modified montmorillonite from Na-montmorillonite. Drawings are not based on proper scale.

Table 1. Compositions and abbreviations of various samples used in this study.

\begin{tabular}{|c|c|c|c|c|c|c|}
\hline Sample Name & Composition & PLA & IFR (MP:PER/1:1) & Pristine Clay & OMMT-1 & OMMT-2 \\
\hline PLA-0 & PLA & 100 & - & - & - & - \\
\hline PLA-1 & PLA/IFR & 86 & 14 & - & - & - \\
\hline PLA-2 & PLA/IFR/MMT & 86 & 9 & $5 \%$ & - & - \\
\hline PLA-3 & PLA/IFR/OMMT-1 & 86 & 13 & - & $1 \%$ & - \\
\hline PLA-4 & PLA/IFR/OMMT-1 & 86 & 11 & - & $3 \%$ & - \\
\hline PLA-5 & PLA/IFR/OMMT-1 & 86 & 9 & - & $5 \%$ & - \\
\hline PLA-6 & PLA/IFR/OMMT-2 & 86 & 13 & - & - & $1 \%$ \\
\hline PLA-7 & PLA/IFR/OMMT-2 & 86 & 11 & - & - & $3 \%$ \\
\hline PLA-8 & PLA/IFR/OMMT-2 & 86 & 9 & - & - & $5 \%$ \\
\hline
\end{tabular}

\subsection{Characterization}

Small-angle X-ray scattering (SAXS) experiments were performed using a line-collimated SAXSess system (Anton Paar, Graz, Austria) operated at $40 \mathrm{kV}$ and $50 \mathrm{~mA} ; \mathrm{Cu} \mathrm{K}_{\alpha}$ radiation with a wavelength of $0.1542 \mathrm{~nm}$ (PAN analytical X-ray source, Eindhoven, The Netherlands) was used. A sample holder (paste-cell) for powder samples was used to examine MMT and OMMTs. A transmission electron microscopy (TEM) instrument, JEOL JEM 2100 HRTEM (JEOL, Tokyo, Japan) operating at $200 \mathrm{kV}$, was used to evaluate the morphology of nanocomposite microtome samples using a carbon-coated grid. Images were captured using a TEM camera (Ultrascan, Gatan, Pleasanton, CA, USA) and Digital Micrograph software (Gatan, Pleasanton, CA, USA). TGA analysis was performed using a TA instrument (model TGA Q500, New Castle, DE, USA) from 30 to $800{ }^{\circ} \mathrm{C}$ with heating rate of $20{ }^{\circ} \mathrm{C} / \mathrm{min}$ under a nitrogen and oxygen gas atmosphere. After a cone calorimetry test, the microstructure of the char residues was recorded using Scanning Electron Microscopy (SEM, AURIGA Crossbeam workstation from Carl Zeiss, Germany) operated at $3 \mathrm{kV}$. To identify the degradable volatile components of the neat PLA and PLA/OMMT nanocomposites, TGA-FTIR was carried out using a PerkinElmer Pyris 1 TGA connected to a Nicolet IS50 Spectrometer (PerkinElmer, Waltham, MA, USA) with a temperature range of 50 to $800{ }^{\circ} \mathrm{C}$ and a heating rate of $20{ }^{\circ} \mathrm{C} / \mathrm{min}$ under a nitrogen atmosphere. About $20 \mathrm{mg}$ of each sample was tested. The fire performance of all the PLA/IFR/OMMT nanocomposite samples and PLA were evaluated by iCone Calorimetry (Fire Testing Technology, East Grin stead, UK according to ISO 5660). Calorimetry test samples with the dimensions of $100 \mathrm{~mm} \times 100 \mathrm{~mm} \times 3 \mathrm{~mm}$ were prepared; the samples were wrapped in aluminum 
foil, leaving the top surface open, and were exposed to radiant cone heating with a $25 \mathrm{~kW} / \mathrm{m}^{2} \mathrm{heat}$ flux. Melt-rheological analysis was performed using a Physica MCR 501 Rheometer (Anton Paar, Graz, Austria) equipped with $25 \mathrm{~mm}$ parallel plates. Time sweep tests were carried out under a normal atmosphere and strain amplitude of $0.5 \%$ (linear region) within a $20 \mathrm{~min}$ period at $190{ }^{\circ} \mathrm{C}$.

\section{Results and Discussion}

\subsection{Structural and Morphological Analysis}

SAXS patterns can generally be used for structural analysis of PNCs, including mode of dispersion (intercalation or exfoliation) of the silicate layers in the polymer matrix. The scattering patterns of MMT (Na $\left.{ }^{+}-\mathrm{MMT}\right)$, two OMMTs, and PLA/IFR/OMMT nanocomposites with different weight percentages of IFR and OMMT loadings are shown in Figure 2. The peak at $q=5.35 \mathrm{~nm}^{-1}\left(d_{(001)}=1.17 \mathrm{~nm}\right)$ corresponds to $\mathrm{Na}^{+}-\mathrm{MMT}$, and after surface modification with different phosphonium derivatives, OMMT-1 and OMMT-2, the peak shifts to lower angles, $q=3.39 \mathrm{~nm}^{-1}\left(d_{(001)}=1.85 \mathrm{~nm}\right)$ and $3.24 \mathrm{~nm}^{-1}$ $\left(d_{(001)}=1.94 \mathrm{~nm}\right)$, respectively, as shown in Figure 2A. This indicates that intercalation of phosphonium compounds into the clay galleries occurs, resulting in an increase in the $d_{(001)}$-spacing, which is in good agreement with previous reports [27,29]. After addition of the OMMT-1 with varying the weight percentages to the PLA, significant changes in the PLA/IFR/OMMT-1 composites were observed in the lower scattering vector region with increasing OMMT-1 concentration, which indicates a formation of highly intercalated nanocomposite structure, as shown in Figure 2B. For the nanocomposites containing 1 and 3 wt.\% of OMMT-1 (samples PLA-3 and PLA-4, respectively), the characteristic OMMT-1 peak shifted to a lower scattering vector, $q=3.23\left(d_{(001)}=1.94 \mathrm{~nm}\right)$ and $3.08\left(d_{(001)}=2.04 \mathrm{~nm}\right)$, respectively, which may be due to further intercalation of the PLA chains in the two-dimensional silicate galleries. In the nanocomposite containing $5 \mathrm{wt}$ \% OMMT-1 (PLA-5), the characteristic peak of OMMT-1 was significantly shifted to lower side with a broader peak, appeared at $q=2.10 \mathrm{~nm}^{-1}\left(d_{(001)}=2.99 \mathrm{~nm}\right)$. Such a result indicates high-level of intercalation occurred in presence of MP and PLA chains enter into the silicate layers. On the other hand, Figure $2 \mathrm{C}$ illustrates scattering patterns for different weight percentages of OMMT-2 containing PLA composites (PLA-6 to PLA-8). In all these nanocomposites, an intercalated nanocomposite structure was observed and in peak not much shifted lower side as compared to earlier.
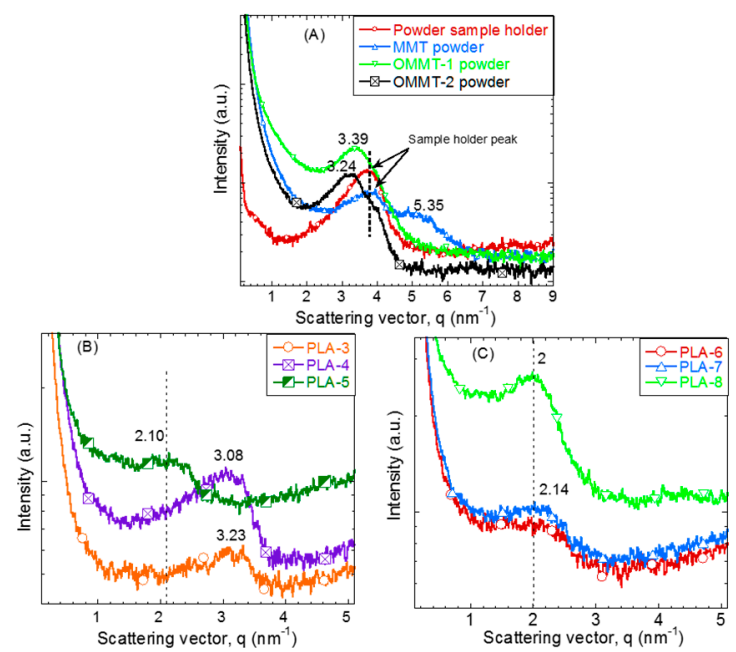

Figure 2. XRD patterns of PLA and different surface-modified OMMT-containing PLA nanocomposites with different weight percentages. (A) OMMTs, (B) PLA/IFR/OMMT-1 nanocomposites, and (C) PLA/ IFR/OMMT-2 nanocomposites.

The TEM images of the representative nanocomposites PLA- 5 and PLA- 8 are shown in Figure 3 at two different magnifications. The images show dark strips in some regions, either related to MMT and 
IFR agglomeration or partially exposed surfaces of intercalated silicate layers, and the thick, light dark lines indicate some degree agglomeration of intercalated silicate layers in the PLA matrix. Moreover, TEM images show that agglomerated and intercalated silicate layers are well distributed in the PLA matrix and the disordered nature of intercalation, which agrees with the presence of lower angle (001) characteristic peaks in the scattering patterns of PLA-5 and PLA-8.

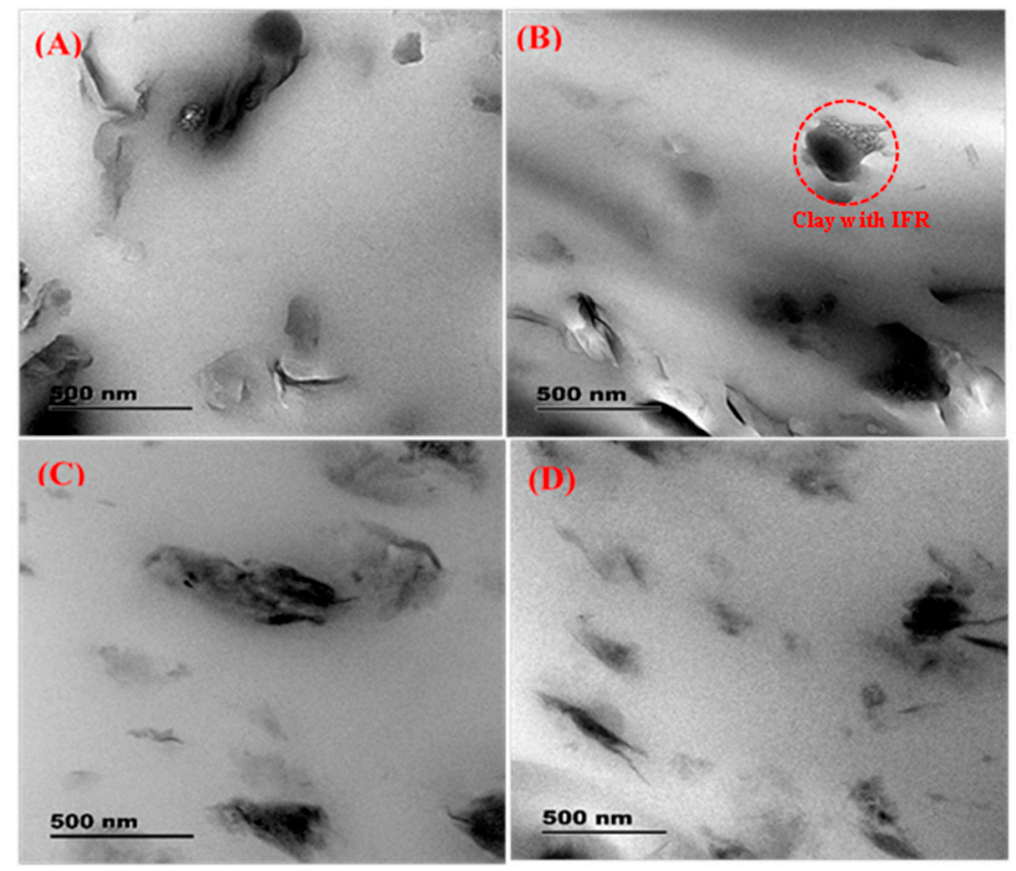

Figure 3. TEM images of PLA/clay nanocomposites. (A) PLA-3, (B) PLA-5, (C) PLA-6, and (D) PLA-8.

The different dispersion characteristics of PLA-5 and PLA-8 nanocomposites can be explained on the basis of flow behavior during processing. Detailed melt-state flow behavior of various samples can be found in Section 3.5. It can be seen that the transient viscosity of PLA- 8 at $190{ }^{\circ} \mathrm{C}$ is higher than that of PLA-5 and remains constant throughout the experiment. However, in the case of PLA-5, the viscosity increases with time. Such increase in viscosity results in increase shear-stress during processing, which facilitates the peeling of silicate layers from the clay-stacks as shown in PLA-3 (Figure 3A) and PLA-5 (Figure 3B). On the other hand, initial higher viscosity, and hence the stress, breaks down clay-stacks into small clay-stacks which hinders the peeling mechanism. For this reason, a large number of small intercalated clay-stacks observed in the TEM image of PLA-6 (Figure 3C) and PLA-8 (Figure 3D).

\subsection{Thermal Degradation Characteristic}

The thermal degradation characteristic of the nanocomposites was studied using TGA and the relevant thermal degradation data includes $T_{\text {deg }}$, defined as the temperature at which degradation started, $T_{\max }$, defined as the temperature at which maximum weight loss occurred, and the percentage of char residue present at $800{ }^{\circ} \mathrm{C}$ in different environmental conditions, such as under an air and nitrogen atmosphere. The TGA plots of neat PLA and various nanocomposite samples are shown in Figure 4 and the characteristic data calculated from various TGA thermograms are summarized in Table 2. With the addition of IFR and IFR/OMMT to the PLA, the initial degradation temperature gradually decreased from PLA to PLA/IFR and then to PLA/IFR/OMMT nanocomposites due to the presence of IFR and IFR/OMMT, which accelerate the polymer degradation to fast char formation that acts as thermal insulation at high temperatures to protect the underlying polymer from further degradation and improve the char residue. However, the combination of IFR with OMMT further increased the char residue because of the high phosphorous content. In this thermal degradation, 
first MP started to decompose and release melamine pyrophosphate and polyphosphates, which further condensed the polymer chains to form char [30]. In addition, the OMMT-1-containing nanocomposites, PLA-4 and PLA-5, improved the char residue, compared with that containing OMMT-2, PLA-7 and PLA-8, because aromatic phosphonium compounds are more resistant to thermal degradation than aliphatic phosphonium compounds. Overall, it was observed that in both the nitrogen and air atmospheres, the thermal degradation phenomenon were similar (Figure 4A,C). However, compared with those of the $\mathrm{N}_{2}$ atmosphere, the air atmosphere improved the early polymer degradation and largely increased the char residue from PLA to IFR/OMMT-1 containing PLA nanocomposites. The relevant values are included in Table 2. Because of the catalytic activity of the MMT during thermal degradation in the presence of oxygen, the surfactant triphenyl phosphonium oxidizes to form a stable triphenyl phosphine and phosphite oxide, which may create a protective barrier on the surface of the polymer to delay the polymer degradation, even at high temperatures [31]. Also, it clearly indicates that PLA-5 produced a high char residue of about $18.5 \%$ at $800{ }^{\circ} \mathrm{C}$. Owing to possible synergistic effects, it has strong thermal oxidative behavior even at high temperatures. Figure 4B,D shows the TGA derivative plots of nanocomposites and the addition of IFR, pristine MMT, and OMMTs to the PLA. The degradation behavior obviously changed from high peak intensity to low peak intensity. With increasing loading of IFR/OMMT to the PLA, the $T_{\max }$ and $\alpha_{\max }$ values were slightly decreased. The decreasing value of $\alpha_{\max }$ with decreasing peak intensity indicates that the presence of IFR/OMMT promoted the PLA degradation at lower temperatures to form thermally insulating char faster, which can prevent further polymer degradation. Therefore, the peak intensity of PLA-5 was lower than that of PLA-8. Also, PLA-8 contained a broad degradation peak, clearly visible in Figure 4B,D, indicating higher degradation. Moreover, the residual char yields at $800{ }^{\circ} \mathrm{C}$ for PLA-5 and PLA-8 were much higher than the PLA-0, as shown in Table 2. All these results suggest that rearrangement reactions occur in between the MMT surface modified by surfactants and IFR, or some decomposed components of PLA, to improve the char residue and char strength, which provide thermal insulation and postpone the material degradation until higher temperatures.
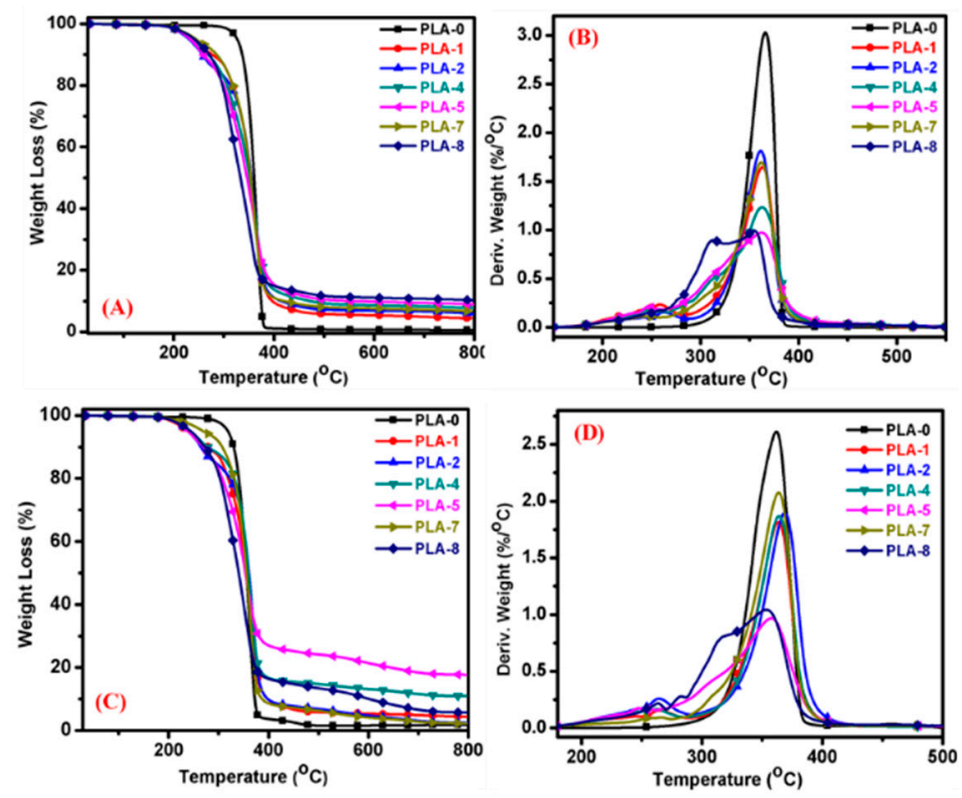

Figure 4. TGA and derivative plots of PLA/Clay nanocomposites with different surface-modified clays and compositions. $(\mathbf{A}, \mathbf{B})$ under nitrogen atmosphere and $(\mathbf{C}, \mathbf{D})$ under air atmosphere. 
Table 2. Characteristic thermal stability date for PLA and various nanocomposites calculated from TGA thermograms.

\begin{tabular}{|c|c|c|c|c|c|c|c|c|}
\hline \multirow[b]{2}{*}{ Samples } & \multicolumn{4}{|c|}{$\mathrm{N}_{2}$ Atmosphere } & \multicolumn{4}{|c|}{$\mathrm{O}_{2}$ Atmosphere } \\
\hline & $\begin{array}{l}T_{\text {deg }} \\
\left({ }^{\circ} \mathrm{C}\right)\end{array}$ & $\begin{array}{l}T_{\text {Max }} \\
\left({ }^{\circ} \mathrm{C}\right)\end{array}$ & $\begin{array}{c}\text { Char at } 800 \\
{ }^{\circ} \mathrm{C}(\%)\end{array}$ & $\begin{array}{c}\alpha_{\max } \\
\left(\% /{ }^{\circ} \mathrm{C}\right)\end{array}$ & $\begin{array}{l}T_{\text {deg }} \\
\left({ }^{\circ} \mathrm{C}\right)\end{array}$ & $\begin{array}{l}T_{\operatorname{Max}} \\
\left({ }^{\circ} \mathrm{C}\right)\end{array}$ & $\begin{array}{c}\text { Char at } 800 \\
{ }^{\circ} \mathrm{C}(\%)\end{array}$ & $\begin{array}{c}\alpha_{\max } \\
\left(\% /{ }^{\circ} \mathrm{C}\right)\end{array}$ \\
\hline PLA-0 & 301.7 & 380.5 & 0.5 & 3.0 & 304.7 & 378.7 & 1.7 & 2.6 \\
\hline PLA-1 & 195.7 & 401.2 & 4.3 & 1.6 & 192.3 & 395.7 & 4.5 & 1.8 \\
\hline PLA-2 & 190.7 & 395.0 & 5.8 & 1.8 & 196.5 & 398.9 & 2.4 & 1.9 \\
\hline PLA-4 & 192.4 & 392.7 & 8.6 & 1.2 & 194.4 & 389.9 & 11.2 & 1.8 \\
\hline PLA-5 & 191.5 & 387.5 & 9.9 & 1.0 & 193.5 & 381.5 & 18.2 & 1.0 \\
\hline PLA-7 & 194.7 & 383.6 & 7.1 & 1.8 & 191.3 & 378.5 & 2.6 & 2.1 \\
\hline PLA-8 & 193.5 & 371.4 & 10.4 & $1.0,0.0$ & 190.8 & 379.8 & 6.0 & $1.0,0.8$ \\
\hline
\end{tabular}

\subsection{Volatile Gaseous Products of PLA Nanocomposites Analyzed by TG-FTIR}

In this work, TG-FTIR was employed to investigate the effect of two OMMTs combined with IFR on the evolution of volatile gaseous components from PLA and PLA/IFR/OMMT nanocomposites during thermal degradation. The FT-IR spectra of the point of maximum weight loss are presented in Figure 5. The spectra indicate that the typical degradation process of pure PLA is almost the same as the PLA nanocomposites, except for small changes in the peak intensities of $\mathrm{CO}, \mathrm{CO}_{2}$, and other peaks. However, during thermal degradation, some gaseous compounds were identified based on their characteristic absorption bands. The main components were $\mathrm{CO}_{2}\left(2360 \mathrm{~cm}^{-1}\right), \mathrm{CO}\left(2136 \mathrm{~cm}^{-1}\right)$, water $\left(3400-3800 \mathrm{~cm}^{-1}\right), \mathrm{NH}_{3}\left(3338,1628,968\right.$, and $\left.931 \mathrm{~cm}^{-1}\right)$, aromatic compounds $(3042,1618$, 1508 , and $\left.698 \mathrm{~cm}^{-1}\right)$, and phosphorous compounds $\left(1282,1086\right.$, and $\left.872 \mathrm{~cm}^{-1}\right)$ [32,33]. Additionally, to understand the changes in the evolved volume of gaseous products during heating of the PLA and PLA nanocomposites, specific components were selected and analyzed.

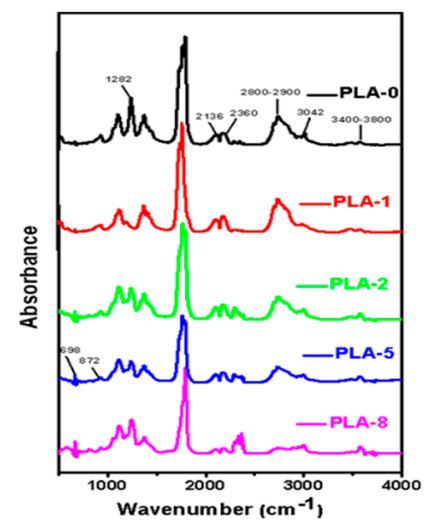

Figure 5. FT-IR spectra of pyrolysis products of PLA and PLA/clay nanocomposites with different surface-modified clay contents at maximum decomposition stage.

The Grams-Schmidt curves are reported in Figure 6A, showing the absorbance of the pyrolysis products with temperature. The absorption intensity of the pyrolysis products decreased from PLA to PLA nanocomposites due to the presence of OMMT improving the char strength and barrier properties. The absorbance vs temperature plots for released $\mathrm{CO}, \mathrm{CO}_{2}$, and carbonyl compounds individually are shown in Figure 6B-D. For all the PLA/IFR/OMMT nanocomposites, the absorbance intensity of the released pyrolysis components was less than that of the unmodified PLA. In the presence of IFR/OMMT, acceleration of the polymer degradation to the formation of a strong char structure occurs, which can prevent further polymer degradation and evolution of combustible components. 
The maximum inhibition in pyrolytic volatile components, such as hydrocarbons, carbonyl compounds, and pyrolytic gases, reduces the heat release rate (HRR), total HRR (THRR), and toxic smoke. Because the volatile hydrocarbons are easily condensed and aggregate as smoke particles, a more dense smoke forms [34]. The addition of modified IFR/OMMT to the PLA subsequently decreased the volume of the released combustible gases and the weight loss, which agrees with the thermal analysis presented in the previous section. It was also observed that the presence of OMMT forms char, which can inhibit the evolution of combustible gases and toxicants. Therefore, the absorption intensities of the gaseous products from PLA-5 and PLA-8 are much less than that of PLA-0, PLA-1, and PLA-2. Moreover, evolution of gases is strongly inhibited in the OMMT-1-containing nanocomposite (PLA-5), because the presence of aromatic phosphonium compounds allows the formation of a strong graphitic crosslinked char structure at high temperatures.
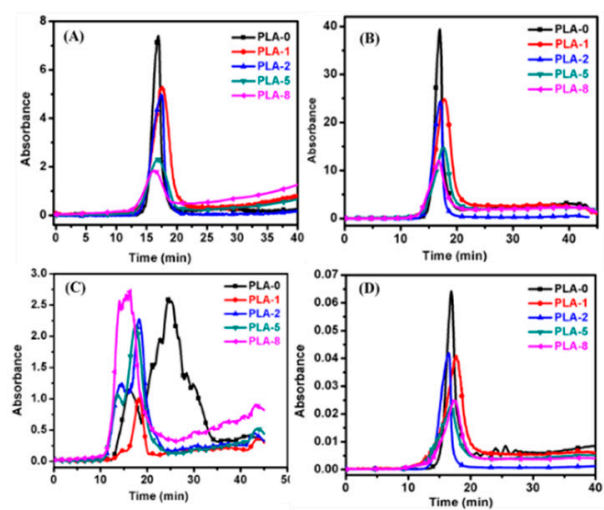

Figure 6. Absorbance of pyrolysis products at complete decomposition stage for PLA and PLA-clay nanocomposites. (A) Gram-Schmidt curves, (B) carbonyl compounds, (C) $\mathrm{CO}_{2}$, and (D) $\mathrm{CO}$.

\subsection{Cone Calorimetry Analysis}

The FR properties of PLA nanocomposites with two different surface-modified MMTs combined with IFR were studied by using cone colorimetry. The obtained results are shown in Figure 7, and the detailed data are summarized in Table 3. The data indicate that PLA-0 burns vigorously after ignition. The pHRR (peak heat release rate) and THRR (total heat release rate) values are $253.7 \mathrm{~kW} \cdot \mathrm{m}^{-2}$ and 37.2 MJ $\cdot \mathrm{m}^{-2}$, respectively. After addition of IFR to the PLA, the values of TTI decreased due to pyrophosphate produced from MP during degradation, which behaves as an efficient catalyst for PLA degradation, causing it to burn quickly under heat flux. However, for the combination of modified MMT and MP-PER to the PLA, the values of TTI (time-to-ignition) further decreased because the MMT also acts as a catalyst in the polymer degradation. Subsequently, the polymer burns in early stage to forms char. The flammability properties mainly depend on the char strength $[35,36]$.

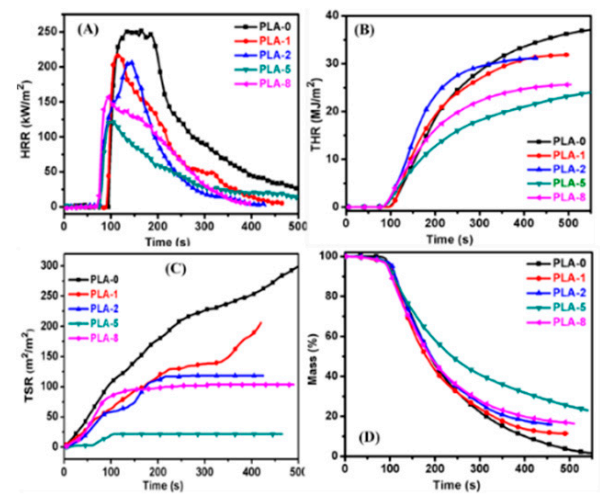

Figure 7. Cone colorimetry test plots of PLA/clay nanocomposites. (A) HRR, (B) THRR, (C) TSR, and (D) MLR plots. 
Table 3. Cone colorimetry data of neat PLA and various nanocomposites.

\begin{tabular}{|c|c|c|c|c|c|c|c|c|c|}
\hline Samples & $\underset{\left(\mathrm{kW} \cdot \mathrm{m}^{-2}\right)}{\mathrm{pHRR}}$ & $\begin{array}{l}\text { TTI } \\
\text { (s) }\end{array}$ & $\begin{array}{l}t_{\text {PHRR }} \\
\text { (s) }\end{array}$ & $\begin{array}{c}\text { THR } \\
\left(\mathrm{MJ} \cdot \mathrm{m}^{-2}\right)\end{array}$ & $\begin{array}{c}\text { FGI } \\
\left(\mathrm{kW} /\left(\mathrm{m}^{2} \cdot \mathrm{s}\right)\right.\end{array}$ & $\begin{array}{c}\text { FPI } \\
\left(\mathrm{m}^{2} \cdot \mathrm{s} / \mathrm{kW}\right)\end{array}$ & $\begin{array}{c}\text { TSR } \\
\left(\mathrm{m}^{2} / \mathrm{m}^{2}\right)\end{array}$ & $\begin{array}{l}\text { TSP } \\
\left(\mathrm{m}^{2}\right)\end{array}$ & $\begin{array}{c}\text { Residue } \\
\text { (wt. } \% \text { ) }\end{array}$ \\
\hline PLA-0 & 253.7 & 92.7 & 142.2 & 37.2 & 1.8 & 0.4 & 295.9 & 37.3 & 1.3 \\
\hline PLA-1 & 216.7 & 88.6 & 126.9 & 31.9 & 1.7 & 0.4 & 204.9 & 31.9 & 11.2 \\
\hline PLA-2 & 205.5 & 72.5 & 139.1 & 31.1 & 1.5 & 0.4 & 118.2 & 31.2 & 16.2 \\
\hline PLA-3 & 161.2 & 75.9 & 121.9 & 28.1 & 1.3 & 0.5 & 24.1 & 27.0 & 11.2 \\
\hline PLA-4 & 154.2 & 76.7 & 118.2 & 26.9 & 1.3 & 0.5 & 21.1 & 26.5 & 16.8 \\
\hline PLA-5 & 120.6 & 73.2 & 109.5 & 25.6 & 1.1 & 0.6 & 09.4 & 21.4 & 22.9 \\
\hline PLA-6 & 181.7 & 77.0 & 115.6 & 26.5 & 1.6 & 0.4 & 125.6 & 29.8 & 09.8 \\
\hline PLA-7 & 164.1 & 70.9 & 84.1 & 25.9 & 1.9 & 0.4 & 98.3 & 25.1 & 13.8 \\
\hline PLA-8 & 163.4 & 69.9 & 89.4 & 24.0 & 1.8 & 0.4 & 102.4 & 27.5 & 15.3 \\
\hline
\end{tabular}

pHRR, peak heat release rate; TTI, time-to-ignition; HRR, heat release rate; THR, total heat release; TSR, total smoke release; MLR, mass loss rate. $(\mathrm{FGI}=\mathrm{pHRR} / \mathrm{tPHRR}$ and $\mathrm{FPI}=\mathrm{TTI} / \mathrm{pHRR})$.

The surface-modified MMT contains phosphonium derivatives which migrate to the polymer surface while burning and form phosphate ester crosslinked compounds with degraded PLA components. The presence of phosphorous improves the char strength and residues. Therefore, the pHRR and THR values of PLA-5 and PLA-8 are significantly lower than PLA-0. Moreover, the OMMT-1-containing PLA nanocomposites exhibited lower pHRR and THR values compared with those of OMMT-2 containing PLA nanocomposites. From Table 3, PLA-5 exhibits the lowest pHRR and THR values of $120.6 \mathrm{~kW} \cdot \mathrm{m}^{-2}$ and $25.6 \mathrm{MJ} \cdot \mathrm{m}^{-2}$, respectively, due to highly dense char formation.

The fire growth index (FGI) and fire propagation index (FPI) are two important factors during the analysis of fire hazards [37]. The calculated FPI values are included in Table 3, which balance the fire risk between ignition and fire growth. The value of FPI for PLA- 0 was, $0.4 \mathrm{~m}^{2} \cdot \mathrm{s} / \mathrm{kW}$, representing the highest fire risk. The FPI for PLA- 5 was $0.6 \mathrm{~m}^{2} \cdot \mathrm{s} / \mathrm{kW}$, hence the fire risk was lower than PLA-0. Similarly, the FGI value indicates the flame spread rate, which decreased from $1.8 \mathrm{~kW} /\left(\mathrm{m}^{2} \cdot \mathrm{s}\right)$ for PLA-0 to $1.1 \mathrm{~kW} /\left(\mathrm{m}^{2} \cdot \mathrm{s}\right)$ for PLA-5. However, for PLA-7 and PLA-8, the FGI values slightly increased to $1.9 \mathrm{~kW} /\left(\mathrm{m}^{2} \cdot \mathrm{s}\right)$ and $1.8 \mathrm{~kW} /\left(\mathrm{m}^{2} \cdot \mathrm{s}\right)$, respectively. These FGI values increased because of the presence of unstable char formed during combustion. To completely reduce the fire hazard, the smoke release must also be reduced. Figure 7C shows the total smoke release (TSR) curves of PLA/IFR/OMMT nanocomposites. It shows that the smoke released from the OMMT containing PLA nanocomposites was strongly inhibited compared with that from unmodified PLA. As shown in Table 3, the TSR and TSP values increased from the OMMT-1-containing nanocomposites to OMMT-2-containing nanocomposites. The likely reason is that cracks in char structure caused incomplete combustion of materials. With incomplete combustion, volatile compounds emerge and condense to form smoke, resulting in increased smoke production. It can be concluded that introduction of OMMT-1 to the PLA improves the char strength and compactness during polymer burning compared with that of OMMT-2, and aromatic phosphonium derivatives on the surface-modified MMT strongly influence the fire performance of polymers due to the formation of highly crosslinked char. Also, it can be seen from Table 3 that, after the cone calorimetry test, there is no char residue left for PLA-0 (more can be found in Section 3.6). However, in the nanocomposites, the amount of char residues significantly increased to $1.3 \%, 11.2 \%, 22.9 \%$, and $15.3 \%$ for PLA-0, PLA-1, PLA-5 and PLA-8, respectively. Plots are shown in Figure 7D, which agree with the TGA results. This indicates that with OMMTs containing PLA composites, the presence of phosphorous causes the char to become stronger and highly compact, protecting the substrate from further degradation and improving the char residue. Moreover, the presence of aromatic surface-modified MMT containing PLA nanocomposites showed high intumescent char and more compactness because of the formation of a graphitic crosslinked char structure, subsequently showing strong FR activity.

\subsection{Analysis of Crosslinked Behavior of PLA Nanocomposites}

Figure 8 shows plots of the storage modulus $\left(\mathrm{G}^{\prime}\right)$ of the PLA nanocomposites as a function of time. To understand the structural alterations with time during degradation, a constant melt temperature 
$190^{\circ} \mathrm{C}$ was used. The time-evolution of the moduli at a $1 \mathrm{rad} / \mathrm{s}$ frequency and $190^{\circ} \mathrm{C}$ was studied. It is well established that the elastic modulus is more sensitive to change in molecular architecture [38].

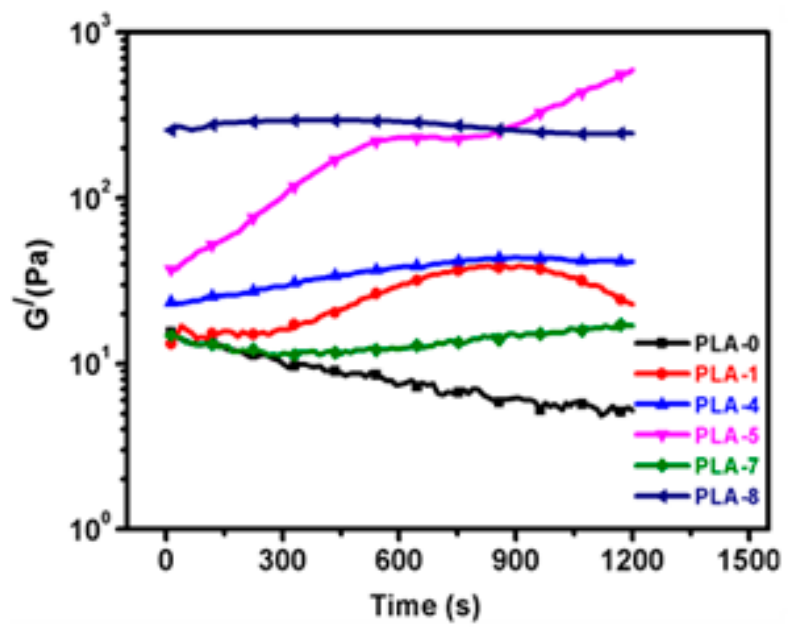

Figure 8. Time-dependence storage modulus $\left(\mathrm{G}^{\prime}\right)$ neat PLA and various sweep test plots of FR PLA/clay nanocomposite samples measured at $190^{\circ} \mathrm{C}$.

During thermal degradation, the IFR tend to undergo cross-linking with PLA, which is clearly supported by the slight upturn in the PLA- 1 curtain intervals in the viscoelastic behavior, as shown in Figure 8. The PLA and IFR may have undergone a post-condensation reaction during the constant shear rate and temperature. Further, Filippone et al. [39] reported that the oxidation of polyethylene terephthalate during time evolution exhibit both chain scission and cross-linking. Further, cross linking reactions dominate the early stage of the tests, resulting in a change of molecular structure due to the increase in the degree of cross-linking. Thus, samples exhibit a rapid growth in viscoelastic behavior. This increase in viscoelastic behavior influences the modulus of the polymer, resulting in an improvement of $G^{\prime}$. For shorter times $(t<500 \mathrm{~s})$, cross-linking is dominated by the chain scissoring reaction. However, the growth rate near gel formation $(t \sim 1000 \mathrm{~s})$ increases rapidly, indicating the cross-linking reaction. For nanocomposites of PLA containing IFR and OMMT (OMMT-1 and OMMT-2), only PLA-5 exhibited a crosslinking pattern, whereas the other samples showed a decrease in modulus with time, indicating absence of cross-linking of PLA. In the presence of strong interactions between the OMMT-1 and MP, more crosslinking occurs, which causes the viscoelastic parameters to continuously increase with time. Another reason may be possible synergistic effects between the OMMT-1 (right amount in the case of PLA-5) and MP, resulting in such unique behavior. Therefore, PLA-5 exhibited superior IFR activity than the other nanocomposites, with the formation of highly compact crosslinked char residue.

\subsection{Char Residue Analysis of PLA Nanocomposites}

The char morphologies of PLA and two different OMMTs containing PLA nanocomposites are shown in Figure 9. All these residual char images revealed that the flame was extinguished by the formation of intumescent char, and all the associated aspects are summarized in Table 3. PLA-0 completely burns and there is no char residue remaining, as shown in Figure 9A,D. However, the addition of OMMT to the PLA greatly improved the flammability with increasing intumescent char residues, as shown in Figure 9B,C,E,F. The char residues obtained from PLA-5 were highly intumescent compact char because less non-combustible gas escaped, resulting in greater height and strength of the char, as shown in Figure 9B,E. As we explained using SAXS and TEM analyses, in PLA-5, a greater degree of delamination of silicate layers occurs during the melt-blending process. We also believe that at this specific composition, there may be strong interactions between the OMMT-1 and MP. Hence, while burning with the clay, the high phosphorous containing compounds migrate to the polymer 
surface and enrich the char residue and char strength. Forming a continuous, highly compact char layer on the substrate results in the excellent FR activity of the PLA-5 nanocomposite system. Another explanation is a possible synergetic effect at this specific composition, because such an improvement in char residue was not observed in the other compositions, PLA-3 and PLA-4. Porous or loose char residues were obtained from PLA-8, as shown in Figure 9C,F, and it is clearly visible that there was less expansion and a lower height of the char. Voids and cracks in the char layer were observed, and the char was not strong enough to inhibit the evolution of volatile components. Therefore OMMT-1-containing PLA composites exhibited better FR activity than OMMT-2-containing PLA composites.

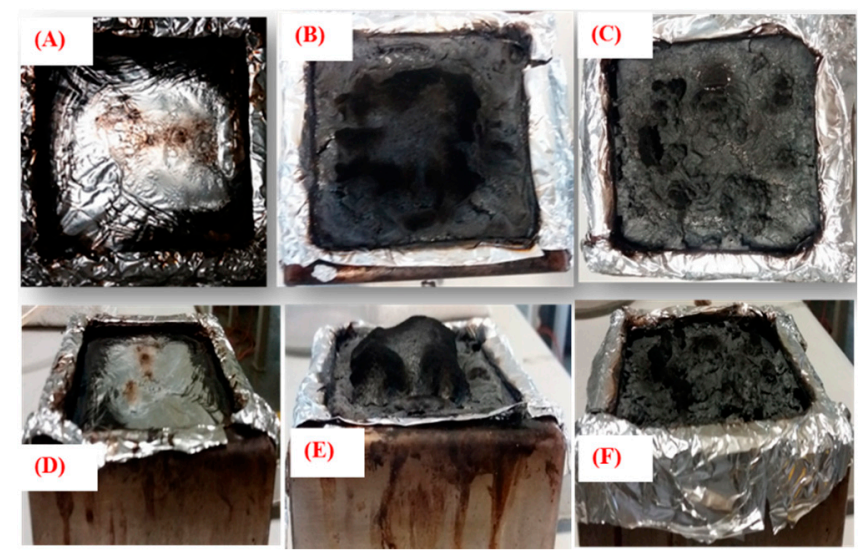

Figure 9. Digital photographs of burning char residues after cone calorimetry test PLA-0 (A,D), PLA-5 (B,E), and PLA-8 (C,F). 1st row for top view and 2nd row for side view.

The SEM images of the residual char of PLA-0, PLA-5, and PLA-8 are shown in Figure 10. Figure 10A clearly shows that pieces of char layers are present. During combustion, a broken char layer and inferior char quality cannot form an effective intumescent char layer to prevent the underlying material from further degradation. Hence, serious melt drippings form and there is no char residue in the case of PLA-0. During combustion, the first stage of MP decomposition releases non-combustible components like $\mathrm{NH}_{3}$ and water along phosphoric acid, which can further dehydrate the polymer chains to form char as we observed in the case of nanocomposite samples. In the OMMT-1, phosphonium derivatives are formed from the surfactant during combustion at high temperatures, creating the possibility for the formation of aryl phosphine, phosphite oxides, and graphitic crosslinked char, resulting in highly compact and strong char, which inhibits the volatile components and toxic gases. The char morphology of PLA-5 is shown in Figure 10B, and it clearly exhibits a highly compact and strong char layer with bubbles, due to the release of pyrolytic components and ammonia gases accumulating inside. These chars can prevent further degradation and melt drippings. Therefore, PLA-5 displayed high FR activity with decreased HRR, THRR, and TSR. The residual char morphology of PLA-8 is shown in Figure 10C. It clearly shows thin char with some cracks and holes. The presence of aliphatic phosphorous compounds and it cannot form the graphitic strong char, hence prevent the formation of graphitic char and the char is unstable. Because of these cracks and holes in the char, volatiles easily escaped. Overall, this indicates that the presence of aromatic phosphorous derivatives contributes to the FR activity, forming a highly compact and graphitic char layer at high temperatures.

Based on the above analyses from TGA, SAXS, rheology, and SEM images of obtained residual chars after cone calorimetric test, it can be found that there is a strong synergetic effect between OMMT-1 and MP. During combustion along with MMT platelets, MP also migrates to the polymer surface, resulting in high crosslinking which can improve the viscoelastic properties of the nanocomposite. Therefore, in the case of PLA-5, a strong synergistic effect is responsible for superior FR activity which is schematically presented in Figure 11. 


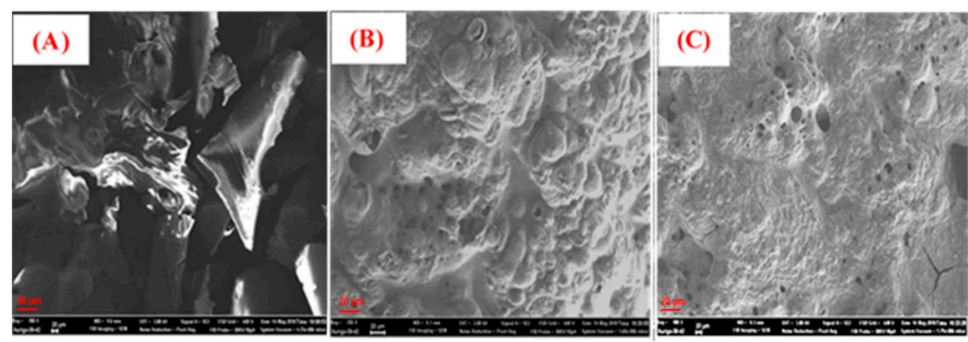

Figure 10. SEM images of the outer surface of char residues of PLA-0 (A), PLA-5 (B), and PLA-8 (C).

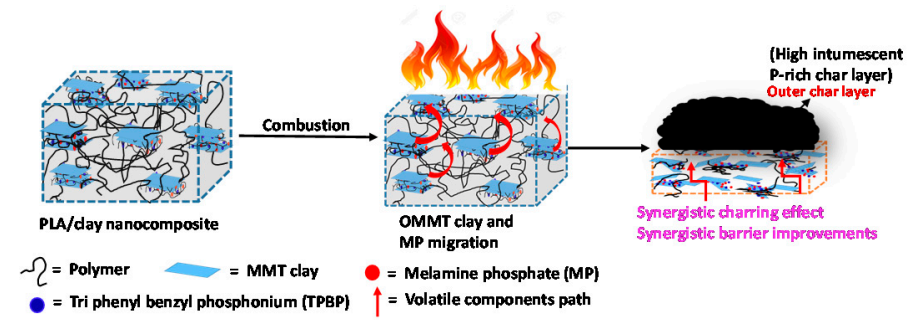

Figure 11. Schematic model to explain synergetic charring formation. Drawings are not to scale.

\section{Conclusions}

A series of FR PLA composites were developed by a melt-extrusion process from an IFR (MP/PER), pristine MMT, and various surface-modified MMTs in the PLA matrix for comparative analysis. The introduction of surface-modified MMTs along with IFR led to remarkable improvements in the charring of PLA nanocomposites, as revealed by TGA and Cone Calorimetry analyses. OMMT-1-containing PLA nanocomposites exhibited a clay composite structure with a lower percentage of intercalation and higher percentage of delaminated nanocomposites. OMMT-2-containing PLA nanocomposites showed an intercalated nanocomposite structure at all weight percentages. At $5 \%$ OMMT-1, the nanocomposite exhibited high FR activity, with low pHRR, THR, TSP, and TSR, because at this specific composition, there might be a possible synergistic effect between MP and OMMT-1. Strong intumescent FR activity with highly compact crosslinked char formation was observed. From absorption curves, it was found that all the modified MMTs containing PLA nanocomposites strongly inhibited toxicant evolution compared with that from pristine clay composites and IFR composites. OMMT-1 strongly inhibited the evolution of all the pyrolytic components. In the presence of phosphorous, the formed char was stronger, strongly inhibited combustible and toxic gas evolution, and exhibited strong FR activity. In summary, it was found that the presence of surface-modified MMTs with aromatic compounds exhibited strong FR activity due to highly cross-linked char structure formation. However, further study is needed to understand the synergistic effect between MP and OMMT- 1 in the case of the PLA- 5 sample.

Author Contributions: K.M. and S.S.R. designed the concept. K.M. processed and characterized nanocomposites; J.B. performed the SAXS experiments, and interpretation of data; all the authors discussed the results and prepared manuscript.

Funding: The authors are grateful to the Department of Science and Technology (DST, project no. HGERA8X) and the Council for Scientific and Industrial Research (CSIR, project no. HGER20S) of South Africa for financial support.

Acknowledgments: The authors sincerely thank to Lesego Maubane for TG-FTIR analysis, and Vincent Ojijo and Prasanna Mural for Cone Calorimetry study.

Conflicts of Interest: The authors declare no conflict of interest. 


\section{References}

1. Ojijo, V.; Ray, S.S. Super toughned biodegradable polylactide blends with non-liner copolymer interfacial architecture obtained via facile in-situ reactive compatibilization. Polymer 2015, 80, 1-17. [CrossRef]

2. Wang, D.-Y.; Gohs, U.; Kang, N.-J.; Leuteritz, A.; Boldt, R.; Wagenknecht, U.; Hinrich, G. Method for simultaneously improving the thermal stability and mechanical properties of poly (lactic acid): Effect of high-energy electrons on the morphological, mechanical, and thermal properties of PLA/MMT nanocomposites. Langmuir 2012, 28, 12601-12608. [CrossRef] [PubMed]

3. Matuana, L.M.; Diaz, C.A. Strategy to produce microcellular foamed poly (lactic acid)/wood-flour composites in a continuous extrusion process. Ind. Eng. Chem. Res. 2013, 52, 12032-12040. [CrossRef]

4. Persson, M.; Lorite, G.S.; Cho, S.-W.; Tuukkanen, J.; Skrifvars, M. Melt spinning of poly (lactic acid) and hydroxyapatite composite fibers: Influence of the filler content on the fiber properties. ACS Appl. Mater. Interfaces 2013, 5, 6864-6872. [CrossRef] [PubMed]

5. Xu, H.; Xie, L.; Chen, Y.-H.; Huang, H.-D.; Xu, J.-Z.; Zhong, G.-J.; Hsiao, B.S.; Li, Z.-M. Strong shear flow-driven simultaneous formation of classic shish-kebab, hybrid shish-kebab, and transcrystallinity in poly (lactic acid)/natural fiber biocomposites. ACS Sustain. Chem. Eng. 2013, 1, 1619-1629. [CrossRef]

6. Dasari, A.; Yu, Z.-Z.; Mai, Y.-W.; Liu, S. Flame retardancy of highly filled polyamide 6/clay nanocomposites. Nanotechnology 2007, 18, 445602. [CrossRef]

7. Zhao, F.; Bao, X.; McLauchlin, A.R.; Gu, J.; Wan, C.; Kandasubramanian, B. Effect of POSS on morphology and mechanical properties of polyamide 12/montmorillonite nanocomposites. Appl. Clay Sci. 2010, 47, 249-256. [CrossRef]

8. Zhou, K.; Liu, J.; Shi, Y.; Jiang, S.; Wang, D.; Hu, Y.; Gui, Z. $\mathrm{MoS}_{2}$ nanolayers grown on carbon nanotubes: An advanced reinforcement for epoxy composites. ACS Appl. Mater. Interfaces 2015, 7, 6070-6081. [CrossRef] [PubMed]

9. Zhou, L.; Ju, Y.; Liao, F.; Yang, Y.; Wang, X. Improve the mechanical property and flame retardant efficiency of the composites of poly (lactic acid) and resorcinol di (phenyl phosphate)(RDP) with ZnO-coated kenaf. Fire Mater. 2016, 40, 129-140. [CrossRef]

10. Zhou, K.; Liu, J.; Wen, P.; Hu, Y.; Gui, Z. A noncovalent functionalization approach to improve the dispersibility and properties of polymer/MoS 2 composites. Appl. Surf. Sci. 2014, 316, 237-244. [CrossRef]

11. Wang, X.; Zhou, S.; Xing, W.; Yu, B.; Feng, X.; Song, L.; Hu, Y. Self-assembly of Ni-Fe layered double hydroxide/graphene hybrids for reducing fire hazard in epoxy composites. J. Mater. Chem. A 2013, 1, 4383-4390. [CrossRef]

12. Wang, X.; Xuan, S.; Song, L.; Yang, H.; Lu, H.; Hu, Y. Synergistic effect of POSS on mechanical properties, flammability, and thermal degradation of intumescent flame retardant polylactide composites. J. Macromol. Sci. 2012, 51, 255-268. [CrossRef]

13. Zhu, H.; Zhu, Q.; Li, J.; Tao, K.; Xue, L.; Yan, Q. Synergistic effect between expandable graphite and ammonium polyphosphate on flame retarded polylactide. Polym. Degrad. Stab. 2011, 96, 183-189. [CrossRef]

14. Zanetti, M.; Camino, G.; Canavese, D.; Morgan, A.B.; Lamelas, F.J.; Wilkie, C.A. Fire retardant halogenantimony- clay synergism in polypropylene layered silicate nanocomposites. Chem. Mater. 2002, 14, 189-193. [CrossRef]

15. Jang, B.N.; Costache, M.; Wilkie, C.A. The relationship between thermal degradation behavior of polymer and the fire retardancy of polymer/clay nanocomposites. Polymer 2005, 46, 10678-10687. [CrossRef]

16. He, X.; Zhang, W.; Yi, D.; Yang, R. Flame retardancy of ammonium polyphosphate-montmorillonite nanocompounds on epoxy resin. J. Fire Sci. 2016, 34, 212-225. [CrossRef]

17. Bee, S.-T.; Hassan, A.; Ratnam, C.; Tee, T.-T.; Sin, L.T.; Hui, D. Dispersion and roles of montmorillonite on structural, flammability, thermal and mechanical behaviours of electron beam irradiated flame retarded nanocomposite. Compos. Part B 2014, 61, 41-48. [CrossRef]

18. Bourbigot, S.; Le Bras, M.; Duquesne, S.; Rochery, M. Recent advances for intumescent polymers. Macromol. Mater. Eng. 2004, 289, 499-511. [CrossRef]

19. Levchik, S.; Balabanovich, A.; Levchik, G.; Costa, L. Effect of melamine and its salts on combustion and thermal decomposition of polyamide 6. Fire Mater. 1997, 21, 75-83. [CrossRef]

20. Reti, C.; Casetta, M.; Duquesne, S.; Bourbigot, S.; Delobel, R. Flammability properties of intumescent PLA including starch and lignin. Polym. Adv. Technol. 2008, 19, 628-635. [CrossRef] 
21. Zhang, R.; Xiao, X.; Tai, Q.; Huang, H.; Yang, J.; Hu, Y. The effect of different organic modified montmorillonites (OMMTs) on the thermal properties and flammability of PLA/MCAPP/lignin systems. J. Appl. Polym. Sci. 2013, 127, 4967-4973. [CrossRef]

22. Li, S.; Yuan, H.; Yu, T.; Yuan, W.; Ren, J. Flame-retardancy and anti-dripping effects of intumescent flame retardant incorporating montmorillonite on poly (lactic acid). Polym. Adv. Technol. 2009, 20, 1114-1120. [CrossRef]

23. Lv, P.; Wang, Z.; Hu, K.; Fan, W. Flammability and thermal degradation of flame retarded polypropylene composites containing melamine phosphate and pentaerythritol derivatives. Polym. Degrad. Stab. 2005, 90, 523-534. [CrossRef]

24. Pang, X.Y.; Tian, Y.; Weng, M.Q. Preparation of expandable graphite with silicate assistant intercalation and its effect on flame retardancy of ethylene vinyl acetate composite. Polym. Compos. 2015, 36, 1407-1416. [CrossRef]

25. Jahromi, S.; Gabriëlse, W.; Braam, A. Effect of melamine polyphosphate on thermal degradation of polyamides: A combined X-ray diffraction and solid-state NMR study. Polymer 2003, 44, 25-37. [CrossRef]

26. Zhu, J.; Morgan, A.B.; Lamelas, F.J.; Wilkie, C.A. Fire properties of polystyrene-clay nanocomposites. Chem. Mater. 2001, 13, 3774-3780. [CrossRef]

27. Hato, M.J.; Choi, H.J.; Sim, H.H.; Park, B.O.; Ray, S.S. Magnetic carbonyl iron suspension with organoclay additive and its magnetorheological properties. Colloids Surf. A 2011, 377, 103-109. [CrossRef]

28. Malkappa, K.; Rao, B.N.; Jana, T. Functionalized polybutadiene diol based hydrophobic, water dispersible polyurethane nanocomposites: Role of organo-clay structure. Polymer 2016, 99, 404-416. [CrossRef]

29. Lai, S.-M.; Wu, S.-H.; Lin, G.-G.; Don, T.-M. Unusual mechanical properties of melt-blended poly (lactic acid)(PLA)/clay nanocomposites. Eur. Polym. J. 2014, 52, 193-206. [CrossRef]

30. Wang, Z.; Lv, P.; Hu, Y.; Hu, K. Thermal degradation study of intumescent flame retardants by TG and FTIR: Melamine phosphate and its mixture with pentaerythritol. J. Anal. Appl. Pyrolysis 2009, 86, 207-214. [CrossRef]

31. Cicero, J.A.; Dorgan, J.R.; Dec, S.F.; Knauss, D.M. Phosphite stabilization effects on two-step melt-spun fibers of polylactide. Polym. Degrad. Stab. 2002, 78, 95-105. [CrossRef]

32. Liu, Y.; Zhao, X.-R.; Peng, Y.-L.; Wang, D.; Yang, L.; Peng, H. Effect of reactive time on flame retardancy and thermal degradation behavior of bio-based zinc alginate film. Polym. Degrad. Stab. 2016, 127, 20-31. [CrossRef]

33. Zhang, W.; He, X.; Song, T.; Jiao, Q.; Yang, R. The influence of the phosphorus-based flame retardant on the flame retardancy of the epoxy resins. Polym. Degrad. Stab. 2014, 109, 209-217. [CrossRef]

34. Dong, Y.; Gui, Z.; Hu, Y.; Wu, Y.; Jiang, S. The influence of titanate nanotube on the improved thermal properties and the smoke suppression in poly (methyl methacrylate). J. Hazard. Mater. 2012, 209, 34-39. [CrossRef] [PubMed]

35. Price, D.; Liu, Y.; Hull, T.R.; Milnes, G.J.; Kandola, B.K.; Horrocks, A.R. Burning behaviour of foam/cotton fabric combinations in the cone calorimeter. Polym. Degrad. Stab. 2002, 77, 213-220. [CrossRef]

36. Schartel, B.; Hull, T.R. Development of fire-retarded materials-Interpretation of cone calorimeter data. Fire Mater. 2007, 31, 327-354. [CrossRef]

37. Gentiluomo, S.; Veca, A.D.; Monti, M.; Zaccone, M.; Zanetti, M. Fire behavior of polyamide 12 nanocomposites containing POSS and CNT. Polym. Degrad. Stab. 2016, 134, 151-156. [CrossRef]

38. Salehiyan, R.; Malwela, T.; Ray, S.S. Thermo-oxidative degradation study of melt-processed polyethylene and its blend with polyamide using time-resolved rheometry. Polym. Degrad. Stab. 2017, 139, 130-137. [CrossRef]

39. Filippone, G.; Carroccio, S.; Curcuruto, G.; Passaglia, E.; Gambarotti, C.; Dintcheva, N.T. Time-resolved rheology as a tool to monitor the progress of polymer degradation in the melt state-Part II: Thermal and thermo-oxidative degradation of polyamide 11/organo-clay nanocomposites. Polymer 2015, 73, 102-110. [CrossRef]

Sample Availability: Samples of the nanocomposites are available from the authors. 